\title{
TABULEIRO DE LETRAS
}

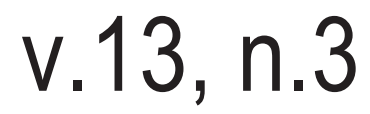

[especial, dez. 2019] 
Catalogação na fonte - Biblioteca Prof. Edivaldo Machado Boaventura / UNEB

Tabuleiro de Letras / Programa de Pós-Graduação em Estudo de Linguagens - PPGEL-UNEB. v. 12 n. 3 (dez 2019) - Salvador: UNEB; 2019.

Semestral ISSN

2176-5782

1. Letras; Literatura; Linguística - Periódicos I. Universidade do Estado

da Bahia. - Programa de Pós-Graduação em Estudo de Linguagens.

CDD-800

CDU-821.134.3

Os textos publicados na revista Tabuleiro de Letras são de exclusiva responsabilidade de seus autores e não refletem necessariamente a opinião daComissãoEditorial e do Conselho Científico. 


\section{TABULEIRO DE LETRAS}

UNIVERSIDADE DO ESTADO DA BAHIA

PROGRAMA DE PÓS-GRADUAÇÃO EM ESTUDO DE LINGUAGENS - PPGEL

REITOR

José Bites de Carvalho

VICE-REITOR

Marcelo Ávila

PRÓ-REITORA DE PESQUISA

Tânia Hetkowski

COORDENAÇÃO DO PROGRAMA

Márcia Rios da Silva (Coord.)

Norma da Silva Lopes (Vice-Coord.)

EDITOR

Ricardo Oliveira de Freitas

EDITOR CIENTÍFICO

Elizabeth Lima

Thiago Prado

COMISSÃO EDITORIAL

Adelaide Augusta de Oliveira

Celina Márcia Abbade

Gilberto Sobral

Sayonara Amaral de Oliveira

ORGANIZADORES DO NÚMERO

Valter de Carvalho Dias

Norma da Silva Lopes

PARECERISTAS Ad Hoc

Adeítalo Manoel Pinho - UEFS

Célia Regina da Silva - UFSB

Gilberto Sobral - UNEB

Rodrigo Oliveira Fonseca - UFSB

Rita de Cássia R. de Queiroz - UEFS
CONSELHO CONSULTIVO

Alana de Oliveira F. El Fahl - UEFS

Alba Valéria Silva - UFBA

Cilza Carla Bignotto - UFOP

Denise Zoghbi - UFBA

Diógenes Cândido de Lima - UESB

Elmo Santos - UFBA

Enivalda Nunes Freitas Souza - UFU Helson Flávio da S. Sobrinho - UFAL

Janaína Weissheimer - UFRN

Josane Moreira de Oliveira - UEFS

José Henrique Santos - UNEB

Kênia Maria de Almeida - UFU

Lígia Negri - UFPR

Maria Cândida Trindade Costa de Seabra - UFMG

Maria Jose Bocorny Finatto - UFRGS

Mairim Linck Piva - FRUG

Nancy Rita Ferreira Vieira - UFBA

Nelly Medeiros de Carvalho - UFPE

Regina Kohlrausch - PUCRS

Rejane Vecchia - USP

Renata Maria de Souza Nascimento - UNEB

Ricardo Postal - UFPE

Tanya Saunders - University of California, EUA

EDITORAÇÃO

Ricardo Oliveira de Freitas

HOMEPAGE E E-MAILS

https://www.revistas.uneb.br/index.php/tabuleirodeletras/in dex

tabuleirodeletras@gmail.com 